\title{
DISTRIBUTED BROKERAGE OFFICES THROUGH INFORMATION TECHNOLOGY
}

\author{
Maxine L. Rockoff \\ Rich Malone
}

Department of Information, Operations, and Management Sciences

Leonard N. Stern School of Business, New York University

44 West $4^{\text {th }}$ Street, New York, NY 10012 


\title{
DISTRIBUTED BROKERAGE OFFICES THROUGH INFORMATION TECHNOLOGY
}

\author{
by \\ Maxine L. Rockoff \\ Clark, Rockoff and Associates \\ One Sherman Square, 30H \\ New York, NY 10023 \\ and \\ Rich Malone \\ Edward D. Jones and Co. \\ 201 Progress Parkway \\ Maryland Heights, MO 63043 \\ June 1991 \\ Center for Research on Information Systems \\ Information Systems Department \\ Leonard N. Stern School of Business \\ New York University \\ $\underline{\text { Working Paper Series }}$ \\ STERN IS-91-13
}

\begin{abstract}
This paper describes some novel ways in which Edward D. Jones and Co., a successful brokerage firm with 1650 offices nationwide, uses information technology to pursue a unique market niche: single-broker offices in communities too small to support a traditional, typically much larger, brokerage branch office. The paper focuses on the use of mainframes with "dumb" CRT terminals, rather than workstations or personal computers, to coordinate distributed operational work on a day-to-day basis.
\end{abstract}

Submitted to COCS '91: Conference on Organizational Computing Systems 
Center for Digital Economy Research Stern School of Business

Working Paper IS-91-13 


\section{INTRODUCTION}

Research on collaborative technology is typically carried out in laboratory settings. This results in large part from an outpouring of technological innovation-especially the networking of workstations - that stimulates researchers to think about exciting opportunities for collaboration enabled by the new technology. The "real world," on the other hand, is often constrained in its adoption of technological advances to use those that are cost-effective, reliable, and can be smoothly integrated into an operational environment.

This paper describes Edward D. Jones \& Co., a successful company that uses information technology in some novel ways to coordinate distributed work on a day-to-day operational basis. The goal of the paper is to help ground research thinking in the nitty-gritty realities, while at the same time stimulating it with respect to new opportunities.

Edward D. Jones \& Co. (EDJ) is a St. Louis brokerage firm with a unique market niche. It places a single broker, together with one assistant, in each of many small communities throughout the nation. EDJ can operate a one-broker branch office profitably in a community that is too small to support a branch office of competitive brokerage firms by providing centrally all of the operations support and managerial functions that are provided locally by overhead personnel in other firms.

EDJ depends critically upon information technology (IT) to meet its strategic goals. In commenting on the contribution of technology, John Bachmann, the firm's Managing Partner, has observed that "DP may not have caused our success, but we couldn't have succeeded without it."

The Data Processing department's mission is to use technology to make the broker feel that support from St. Louis is as close as it would be if it were in the next room. In achieving this "next-room" objective, EDJ has introduced more than the usual IT components of networked computers, in effect broadening the definition of organizational computing to include such other IT components as remotely controlled VCRs for recording corporate video transmissions, barcode subsystems for printed document routing, and a voice PBX facility.

In a manner of speaking, the firm breaks up each of its branch offices, putting the broker and assistant in the field while moving the manager and operational support to central headquarters. Brokers and their assistants are working with people hundreds of miles away as effectively as - perhaps even more effectively than - they would be if they were in the same physical location. Field and headquarters staff work collaboratively at a distance.

This paper describes how EDJ uses IT and accompanying organizational designs to link the brokers and their assistants in the branch offices with personnel at headquarters. What makes 
the company interesting from the point of view of organizational computing is the way it uses its workhorse transaction processing systems, not only to carry out the day-to-day business of the firm, but also for a large number of unusual applications that make it possible for EDJ to provide a high level of personalized headquarters support to its field personnel.

We highlight three aspects of EDJ's use of information technology:

1) EDJ accomplishes its headquarters-field linkage by means of remote CRT terminal/mainframe technology, i.e. without using personal computers. Because workstations with local processing capability have become so much a part of the paradigm of cooperative work, it is unusual to find "dumb" terminals playing significant roles in sophisticated organizational applications.

2) A single mainframe-based relational database provides an essential integrative function for all of the firm's information technology. The database is used not only for storing and retrieving company-critical data such as account information, but also for supporting day-to-day operational procedures, such as the company's central messaging system and a system for monitoring documents in transit.

3) The design of the company's headquarters and field organizations parallels its information technology design; both designs are intended to foster a high level of personalized interaction between headquarters and field personnel.

\section{BaCkground on Edward D. Jones \& Co. AND its Systems ARChitecture}

\subsection{The Firm}

Privately held, Edward D. Jones \& Co. was founded in 1922. It is headquartered on a 50-acre campus in a suburb of St. Louis, Missouri, where it currently employs about 1100 people. As of year-end 1990, EDJ had 1,650 branch offices. If EDJ were publicly held it would rank in the top $12 \%$ of the Forbes "200 Best Small Companies."

EDJ's overall mission statement, "Provide reliable products and services from convenient locations throughout America," is oriented toward the "serious money" of its target clientele. The firm offers conservative investments including stocks, bonds, mutual funds, insurance, real estate limited partnerships, certificates of deposit, treasury securities, etc. The firm does not offer commodities or options, and brokers do not receive commissions for selling "penny stocks," i.e., stocks that sell for less than $\$ 4$ per share. EDJ considers a community's local bank, rather than some other brokerage firm, to be its most serious competitor. 
A typical EDJ branch office, located in a small town or in a suburb of a larger one, has one broker, who is called an Investment Representative or "IR," and an assistant, called a Branch Office Administrator or "BOA," who performs secretarial and front-office operations functions. After an IR trains in St. Louis, he or she must set up in his or her community and overcome successive hurdles, the first of which is meeting 1,000 townspeople individually. This is consistent with the EDJ philosophy that brokers become community members-neighbors and friends.

Brokerage is a highly complex service business that is regulated by a host of entities including the Securities and Exchange Commission, the New York Stock Exchange, state licensing authorities for securities and insurance, and so forth. All brokerage firms are responsible for supervising the activities of their brokers, and most brokerage firms have in their branch offices managers who, having passed special licensing examinations, carry much of the supervisory burden with backup from the firm's headquarters. In contrast, EDJ performs such managerial supervision centrally, out of St. Louis.

In the branch offices of most brokerage firms there are also operations personnel who help the brokers with the myriad operational details of opening accounts, receiving, transferring, and delivering securities, receiving and disbursing cash, etc. As with managerial functions, EDJ provides support for these operational functions centrally from St. Louis.

The branch offices of other brokerage firms - offices that have managerial and operational personnel who are not generating revenue-must be staffed by a relatively large number of revenue-generators (i.e., brokers) over whom to spread these local overhead costs. For this reason, most brokerage firms cannot afford to operate in communities that are too small to support an office having several brokers. This provides EDJ with its particular market niche, since there are thousands of towns in America that fit this description. With 1650 branch offices as of year-end 1990, EDJ had more branch offices than any other brokerage firm in the country.

\subsection{IT-Hardware and Telecommunications}

EDJ initially developed its one-broker-per-branch strategy in the mid-1950's with relatively little technology. The firm used the U.S. mail to send written product information to each branch office on a weekly basis. From 1955 through 1978, brokers used a teletype system to message headquarters, to receive stock quotes and up-to-date product information such as bond inventories, and to place orders. The response time for a stock quote was about thirty minutes.

In 1979 EDJ adopted an aggressive growth strategy and simultaneously undertook a major commitment to information technology. One of the authors (Malone) joined the firm at this 
time as General Partner for Data Processing. Under the new commitment to IT, EDJ's first large central computers, two Hewlett Packard 3000's, were installed. Burroughs CRT terminals and impact printers were installed in each branch office and throughout the headquarters offices." The branch office terminals and printers were connected to St. Louis via multi-point 2400 baud lines installed by, and leased from, AT\&T. Of interest, EDJ's early geographical expansion strategy was dictated in large measure by what towns could be reached cost-effectively by extending these leased lines!

In 1985 the company converted to an IBM mainframe with an IDMS database and CICS telecommunications processing. The Burroughs terminals were left in place both in headquarters and in the branch offices; a special IBM Series 1 interface was built to enable the Burroughs terminals to emulate IBM 3270 terminals to provide access to the new mainframe.

1987 saw the introduction of a supplementary VAX cluster serving over an optical fiber Ethernet interconnecting 1100 DEC terminals throughout the company's headquarters campus, which has six buildings spread over 50 acres. This DEC sub-system provided office automation capability, of which word processing was most important, to virtually all of the headquarters staff. All DEC terminals were set up with 3270 emulation routines to permit them to replace the Burroughs terminals on headquarters desks. To go into 3270 mode, a user had only to hit one reserved "hot" key.

The branch offices retained their 3270-emulating Burroughs terminals, but starting in 1989 the company replaced the impact printers with desktop laser printers in every branch office as well as throughout the headquarters campus. The initial goal was to print in the branch offices all trade confirmations and other documents that had previously been printed in St. Louis on specialized forms and mailed to customers or to the branch offices. In achieving this goal the company negotiated with Dataproducts, its desktop laser printer vendor, to create a special font cartridge that includes several sizes of EDJ's logo.

In 1989 the company installed its own satellite communications system to replace the leased telephone lines, which had been upgraded to 4800 baud in 1982, for providing data communications to all of its branch offices. The satellite system is also used for full-motion corporate video broadcasts by leasing additional transponder capacity on an as-needed basis.

\footnotetext{
"Burroughs was one of the few vendors willing to commit to providing the prompt service EDJ required in all of its locations; it already had a service network that covered the small towns in which EDJ operated, in which it had historically sold equipment to local banks.
} 


\subsection{IT $\rightarrow$ Software}

Five "workhorse" applications were initially built for the Hewlett Packard mainframes in 19791980: Customer Account Processing for keeping track of customers and their holdings; Trades Processing for entering and routing securities transactions; Info, a videotex-like information retrieval system for maintaining both product and procedure information on-line; Quotes for obtaining stock quotes; and Request/Respond for sending messages. When EDJ converted from HP to IBM in 1985, all of these applications were rewritten to run on the IBM mainframe under IBM's CICS transaction processing system using IDMS, Cullinet's mainframe relational data base system (that has since been sold to Computer Associates).

As of 1990, EDJ had 43 major applications. The fact that all of the company's application programs have been written since 1985 , using in common a single database with careful attention from a designated Database Administrator, gives EDJ an important technological advantage over many of its brokerage competitors, who often confront a hodgepodge of applications built over the last twenty five or even thirty years. ${ }^{1}$ For example, EDJ has a single customer name-and-address file, and every product purchased by that customer links to a single name and address. In contrast, the country's largest brokerage firm has customer names internal to 65 different application programs. ${ }^{2}$

\section{Organizing Functionally and Technologically to Provide "Next Room SUPPORT"}

\subsection{Request/Respond}

An important application program is "Request/Respond," which includes a sophisticated version of electronic mail and is one of EDJ's essential tools for enabling a centralized operations staff at headquarters to provide all of the routine support functions needed by the IRs and BOAs. It is also used by managers to keep track of assignments of responsibility.

Request/Respond's sophistication is not in its user interface (which in a simple mainframe terminal leaves much to be desired) but rather in its use for routing, tracking, and managing the communication events involved in running the firm. Request/Respond is also used synergistically by other application programs, as will be illustrated in examples below. In this section we describe several aspects of Request/Respond.

The sender of a message can formally request a response, and this is noted by the system; the request obligates the person receiving the message to respond to it. Request/Respond also incorporates a "reminder" function: When a person signs on to the system, he or she receives 
a system message as to the number of outstanding responses for which that person is responsible, and that number appears continuously on a status line at the bottom of the screen.

The EDJ headquarters telephone book is available on-line. It has an alphabetic section that lists the name, telephone number, and department of every person in the company. Each person's personal USERID for receiving a Request/Respond message is also listed. Of interest, and relevant to the company's integration of its various data processing applications through IDMS, the telephone book is automatically updated by EDJ's Human Resources System application program.

A separate departmental section of the telephone book has been designed to support the field's need for assistance. It lists functions-e.g., Lost Certificates, Market Information and Microfilm Services-in addition to more traditional departments such as Data Processing and Mutual Funds, thus serving as a "yellow pages" for problem resolution. Each listing has a named contact and a functional USERID; the named contact may change as personnel changes occur, but the functional USERID does not. This enables IRs and BOAs to send messages to a service function as well as to a named individual.

Thus, Request/Respond supports "roles" in the sense of Holt ${ }^{3,4}$ in which a function in headquarters can be assigned responsibility by a broker who needs assistance on behalf of a customer. Several designated individuals in the corresponding departmental workgroup are assigned the authority — and the responsibility — to "assume" the function's role, which involves reading the Request/Respond message and carrying out whatever actions are required to solve the problem. In a planned enhancement to Request/Respond, all of the personnel in a headquarters support group will be kept apprised of all open response requests to that group as a whole.

All of the Request/Respond messages (as of year-end 1990 running at about 20,000 per day) are maintained on-line in the IDMS database for 30 days, and are then permanently archived on tape. The on-line messages can be retrieved with various CICS transactions; for example, an individual user can list all of the messages he or she has sent in the last 30 days and then can retrieve any of the messages for viewing.

At this time the Request/Respond messages are free-form and are only indexed by sender, receiver, time, and date. The firm is now examining options for storing the messages on optical disk, which would be considerably cheaper than storage on magnetic tape. When the conversion to optical disk is undertaken, the company plans to put on the messages additional indexes, such as account number if the message pertains to a specific account. Some additional text-oriented retrieval capabilities are also planned, which will give Request/Respond some of the features of Lotus' Notes product. $^{5}$ 
Numerous reports about Request/Respond traffic have been created to help the St. Louis department managers do their jobs. Such reports include average and peak message loads by department, average time to respond to a message for which a response has been requested, listing of all pending messages, listing of all messages from a particular USERID to another particular USERID, and all messages received or sent within a specified time period by region or state.

\subsection{Departmental Organization}

The firm organizes personnel physically as well as through IT to achieve its goal of providing support from St. Louis as though the support personnel were in the next room. When several people are assigned to a particular function in headquarters, they are physically co-located and serve the field more or less interchangeably. In this way, personnel absences-whether due to vacation, to illness, or to someone's just being temporarily away from his or her desk-do not result in unanswered messages or interminable telephone tag.

The branches throughout the country are divided into four geographic areas, and the larger headquarters support groups are correspondingly divided. For example, the Mutual Funds support group has twelve people altogether and is divided into four subgroups of three people each, with one subgroup assigned to each area. This helps personalize the support function for both the branch and headquarters personnel. That is, the IR and BOA in a branch interact on a day-to-day basis with only two or three people in Mutual Funds instead of twelve. Furthermore, each headquarters support person has to deal only with $400+$ branches instead of 1650 .

When an IR or BOA sends a Request/Respond message to a support group that is geographically subdivided, the system automatically routes the message to the subgroup servicing that IR's or BOA's branch. The centralized relational database, IDMS, simplifies the programming enormously.

Of interest, the electronic mail feature of DEC's ALL-IN-ONE office automation software was disabled when ALL-IN-ONE was installed with the VAX cluster on the headquarters campus in 1985. This was done so that anyone who wanted to send a message would have to continue using Request/Respond on the mainframe, with its associated tracking and assignment-of-responsibility capabilities.

In integrating its VAX cluster into its IBM mainframe environment, EDJ has had to wrestle with a multi-vendor user identification problem. Initially the DEC and IBM IDs were different, but EDJ fairly promptly fixed this problem to preserve the uniqueness of identifier across the two subsystems; this was a difficult task at the lower level of systems programming, but necessary in order to maintain functional smoothness from the user's point 
of view. Now when a headquarters person signs on to the system at a DEC terminal with a DEC ID and "hot-keys" into 3270 mode for a CICS transaction, the correct IBM ID is automatically and transparently assigned to the CICS session.

\subsection{Corporate Television}

EDJ has had a television production facility since 1982, during which time each branch has been equipped with a video cassette recorder (VCR). Marketing and other departments call upon the production facility to produce promotional programs for new products, training programs for new CICS transactions and various operational procedures, and so on. Some of the programs are targeted at the IR, some at the BOA, and some at both. Some programs are also meant to be viewed by customers.

When the company installed its satellite data communications system it chose a system that could also transmit full-motion television. Satellite distribution has cut weeks off of the time it had taken to duplicate and distribute copies of a new video to each of the branches. Cost reductions for copying and mailing the tapes are also significant.

When a pre-recorded or "canned" television program—such as one that introduces a new product-is going to be broadcast, headquarters sends out an "all points bulletin" on Request/Respond, alerting the IR or BOA to leave a blank tape in the branch VCR. The company uses inexpensive ( $\$ 300$-per-hour) satellite time in the middle of the night to broadcast the program to all branches. Electronic signals in the broadcast stream turn on the VCR, cause the program to be recorded, and then rewind and turn the VCR off.

Request/Respond is also used to notify the branches of an upcoming "live" broadcast or teleconference. Although the firm had in the past arranged ad hoc teleconferences employing rented facilities, these teleconferences occur much more frequently and spontaneously now that the satellite installation has been completed. An interesting example was a live teleconference in support of a new internationally-based mutual fund. The teleconference broadcast originated from EDJ's studio in St. Louis with the fund's managers participating live from Geneva and Los Angeles via satellite links. Many of the branch offices invited customers to view the teleconference as it was being broadcast, and customers as well as IRs could call in questions during the program. The one-hour program was taped and edited, and the result was broadcast to the branch office VCRs at night. IRs could then invite in additional customers to see the program in its canned format; although they couldn't then ask questions of the fund managers, they could hear the questions that had been asked by other customers and the managers' answers.

EDJ firmly believes that the teleconferences and videos are important for personalizing the headquarters personnel to the field personnel, especially to BOA's who have never been to 
St. Louis. Thus, video broadcasts take their place with the firm's regional organization and other techniques for helping make the personnel in the one-broker branch offices feel part of the EDJ community.

EDJ's ability to distribute television programming and teleconferences to the branches is a byproduct of the $\$ 30$ million satellite communications installation which was cost-justified solely on the basis of replacing the multi-point leased telephone lines for the Burroughs terminals in all of the branches.

\subsection{Branch Cashiering}

In this section we describe the Branch Cashiering System, a suite of IT applications that illustrates how operational support for a branch function, one that is handled by specialized in-branch operations personnel in other firms, is handled centrally by EDJ.

Until 1989 each branch office packed up the securities certificates, checks, and cash it received each day in a pouch that was mailed to St. Louis or to one of four regional processing centers the company had established in Atlanta, Milwaukee, Seattle, and Dallas. The centers had responsibility for crediting the appropriate customer accounts and for depositing the funds in a bank account in the regional location. The regional centers had been established in the mid-1980's to cut down the length of time it took for funds to be deposited in customer accounts - three or four days instead of four or five days, the latter a penalty of operating in small towns where Federal Express, courier services, and other infrastructure elements are often absent. Timely receipt of customer funds is a critical function for the firm because of special regulations that penalize a brokerage company for securities transactions that are not settled (i.e., covered by funds) within a specified number of trading days, usually five.

In 1989, EDJ decided to decentralize this operational cashiering activity to the branch offices themselves. First, EDJ negotiated with a St. Louis money center bank which agreed to set up within its own system an application program that would allow the bank to communicate electronically with EDJ. Next, a local bank was identified for each branch office and an EDJ account was opened in that bank. Each branch office now deposits daily any funds it receives into its local bank account, and all of the branches' local bank accounts are swept nightly by EDJ's bank in St. Louis.

IT support for Branch Cashiering is as follows: When a check or cash comes into the branch, the BOA logs it into the customer's account via a CICS transaction; a receipt for the customer is immediately and automatically printed on the laser printer using data from the customer's account from the IDMS database. This provides a feedback loop that helps with quality assurance, especially if the customer has visited the branch personally instead of sending the 
funds through the mail, since the BOA and the customer can review the transaction at once. The receipt has the account name and other identifying information on it; if the BOA has made an error in typing the account number or in choosing the correct account from several in the same name, the error is caught at the input source. (In firms with less automation, the receipt is typed on a typewriter and the data processing entry is typed separately, an errorprone procedure.)

The Branch Cashiering system on the mainframe totals all funds received by each branch and sends a message automatically to the message line at the bottom of the BOA's terminal onehalf hour before the local bank closes, to remind the BOA to make the deposit. The BOA "reports" the deposit after it has been made, using a CICS transaction that credits the appropriate customer accounts and, in turn and automatically, tells the St. Louis bank how much to sweep from the local bank.

The firm had been borrowing $\$ 20$ to $\$ 25$ million per day to run the business, for example to cover customer transactions for which customer funds had not been received; now it invests that much each day in overnight securities. The firm's net interest income had been $\$ 350,000$ per month; now it is $\$ 800,000$. Moreover, customer funds are invested faster in interestbearing money market funds, which helps Edward D. Jones \& Co. in its competitive battle for the assets of conservative investors.

\subsection{Document Tracking System}

Each branch receives numerous legal, account-related documents that all brokerage firms are required to keep on file. These include authorization letters such as those a customer must sign in order to have duplicate statements sent to another party, trust documents for accounts that are opened in the name of a trust, etc. EDJ does all of this archiving centrally in St. Louis, whereas other firms that have authorized operations and managerial personnel in the local branch usually keep the documents locally.

EDJ has installed a Document Tracking system to support this function. When a customer's document is received at the branch, the BOA uses a CICS transaction to log the document into the customer's account. A cover sheet to accompany the document to St. Louis is simultaneously printed on the laser printer at the branch, with as much pre-filled account information from the IDMS database as possible. The document is then signed by the customer if necessary, either by having the customer come to the office or by mailing the cover sheet to the customer.

At the same time that the system prints the cover sheet, it initiates a tracking procedure with a follow-up schedule determined by how long the document should take to get to headquarters, through the U.S. Postal Service or other alternative. When the system prints the cover sheet, 
it prints the name of the department the document should be sent to, e.g., Mutual Funds, Bonds, New Accounts, and so forth, and it also prints a bar code to identify the transaction. When the document arrives in the mail room in St. Louis it is routed to the department listed on the cover sheet. When the document gets to the department, the cover sheet is scanned by a bar code reader. At this step, the document is automatically "checked off" in the document tracking system via a CICS transaction that is initiated by the bar code reader in the destination department. If a document hasn't been checked off by its pre-set time, a Request/Respond message is automatically sent by the Document Tracking system to the appropriate department, and to the branch office, for follow-up. The Document Tracking system is an example of an automated office procedure ${ }^{6,7}$ with closure provided by a tickler list maintained by the system on what would otherwise be an open-loop procedure.

The use of printed bar codes on the document cover sheets and the participation of the bar code readers in the operations departments in headquarters is somewhat analogous to what Federal Express has done with bar code readers to track packages in transit. ${ }^{8}$

The document tracking system has reduced costs to the firm and increased the firm's service quality as follows:

First, because there are so many different kinds of documents, there had been many different kinds of cover sheets and BOAs frequently erred in pulling the right one from the supplies shelf; the system causes the correct cover sheet to be printed. These errors had to be corrected by someone in the headquarters department who sent a message back to the branch to ask for the correct form. When known to the customer, such errors were particularly troublesome to the firm, as when the branch had to arrange for the customer to sign the correct form. In addition to reducing errors, the installation of the system has meant that branches no longer have to stock pre-printed multi-part forms.

Second, the system has dramatically reduced the number of lost documents, which had been a perennial problem in headquarters.

Third, the headquarters headcount has been reduced: A five-person document filing department has been eliminated completely as a direct result of implementing the document tracking system, and four to five scattered positions have been eliminated in other departments.

\subsection{Integration of Voice Communications}

EDJ has a Rolm PBX linked to its IBM mainframe. An automated answering system on the PBX is used to route calls made from the branch offices to headquarters using a special 800 number. When a branch office calls the 800 number, the caller is required to touch in his or 
her branch ID as a first step in the call's processing. This ID is passed to a mainframe program that accesses the IDMS database for information about the branch, such as whether the call should be routed by the PBX to a subgroup's phone within the headquarters department being called.

A planned application program will retrieve a summary of calls made by that branch to headquarters over the 800 number. The call notes will be stored in the IDMS database and the summary will appear in reverse chronological order in a queue, ready for the person responding to the call to retrieve with a single key stroke. When the call has been completed, the person who answered the call will be responsible for writing up a call note, which will then go into the database.

\section{Discussion}

The description above shows that Edward D. Jones \& Co. is a noteworthy example of a large company that has created what we would today call "coordination technology" or "groupware" for running its day-to-day operations. Several summary observations are in order.

\subsection{Mainframe Technology vs. Workstations/Personal Computers}

Given that most ideas concerning workgroup computing and collaboration technology are workstation- or personal computer-based, ${ }^{9}$ EDJ's use of dumb terminals connected via 4800 baud lines to a central mainframe may seem anachronistic. Admittedly, the EDJ applications suffer from the inconvenience and lack of user-friendliness that generally characterize mainframe transactions accessed by distant terminals. ${ }^{10}$ The company would like to provide local processing capability in the branch offices to improve the user interface and to facilitate office automation capabilities, but has not yet been able to cost-justify them by identifying sufficient productivity enhancements and cost-displacements, as was possible when introducing the satellite data communication system. In the real world costs matter.

\subsection{Integration}

The disadvantages of not having local processing capability are offset by the advantage of a single, company-wide, integrated IT system to achieve coordination. The IDMS database is arguably the most important integrative aspect of EDJ's systems. An unusual aspect of IDMS' utility in the EDJ environment is that it facilitates operational procedures, such as the routing of Request/Respond messages and phone traffic. The power and utility of a central database-or alternatively of decentralized data that can be retrieved from a single perspective-are well understood, though most frequently in the context of management information systems such as those used for decision support. ${ }^{11}$ 
Request/Respond is the company's primary coordination tool. While it resembles and encompasses electronic mail, it was developed as an operations tool-for example, to facilitate communications on behalf of customers-as well as a managerial tool for assuring that assignments of responsibility are tracked. In these respects, Request/Respond works primarily for the organization whereas e-mail in most organizations works primarily for the individual.

EDJ's "next room support" depends on the integration of its coordination tools with its workhorse transaction processing systems. The IDMS database stores information about branch offices, brokers, customers, customer holdings, and so forth. Applications such as the Document Tracking system rely on several of these pieces of information to keep track of what documents are in transit, to decide how long the documents should take in transit before they are considered "missing," and to retrieve the correct address for the alert message when a document has been determined to be missing. All of these improve performance in the business arena.

Thus, although EDJ's coordination tools have many of the characteristics of coordination products, such as The Coordinator, ${ }^{12}$ for assigning responsibility and operating actively, their coordinating power lies in the extent to which they are integrated with the EDJ's companycritical transaction processing systems.

\section{3 "Information Technology" Broadly Construed}

Edward D. Jones \& Co.'s information technology infrastructure includes more than computers and telecommunications components; it incorporates voice PBX, bar code readers and video cassette recorders as well. These components are integrated with the rest of the information technology and with the company's organizational design in ways that IT system designers

might not ordinarily think of. An example is the IDMS database and the Request/Respond system used together with the satellite data distribution system to send an all-points-bulletin alerting the branch office personnel to the need for putting a tape into the VCR, and then later for controlling the VCR via special signals in the broadcast stream.

Given its strategic goal of "next room support," EDJ requires substantial parallelism between its organization and information system designs. IT is known to enable reorganization of centralized workgroups, as found for example in the insurance industry, ${ }^{13}$ and also to facilitate decentralized operations, as in the operation of Mrs. Fields' Cookies. ${ }^{14,15}$ EDJ relies on a combination of the two.

In summary, Edward D. Jones offers a case study of a profitable firm in which information technology is used pervasively to enable an unusual organizational design. Its lessons of insistence on integration, the possibility of achieving impressive results with imaginative use 
of less impressive technology, and the need to organize human systems in conjunction with their technological support counterparts, may be useful to a broader community as we move toward organizational computing systems for globally distributed businesses.

\section{ACKNOWLEDGEMENTS}

The authors would like to acknowledge the contributions of the data processing staff at Edward D. Jones \& Co., whose dedicated efforts over the past twelve years brought into being the systems described in this paper. Special thanks go to John Caruso, Terry Tucker, and Wes Clark who commented on the paper, and to Pat Brown who supplied many of its details.

The collaboration of which this paper is a part began in 1987 when Clark, Rockoff and Associates started a consulting assignment with Edward D. Jones. The collaboration technologies employed in writing this paper were those of fax and phone.

\section{REFERENCES}

1. Wall St. brokerages struggle to upgrade outdated information systems MIS Week 1050 (Dec. 18, 1989), $1 \& 19$

2. DuWayne Peterson, Executive Vice President, Merrill Lynch, personal communication, 1989

3. Holt, Anatol W., Roles and Activities, Mimeo, Incomplete draft, March 30, 1979

4. Holt, Anatol W. and Paul M. Cashman Designing systems to support cooperative activity: An example from software management. In Proceedings of IEEE Computer Society's 5th International Computer Software and Applications Conference (Nov.). IEEE Computer Society, Los Alamitos, Calif., 1981, 184-190

5. Lotus Notes InformationWeek (Dec. 11, 1989) 14 (Note to reviewers: We realize that this is probably not the best reference for Lotus' Notes product; we are waiting for a call back from Irene Greif for a better one.\}

6. Zisman, Michael D. Representation, Specification and Automation of Office Procedures Doctoral Dissertation, University of Pennsylvania 1977

7. Meldman, Jeffrey A. A New Technique for Modeling the Behavior of Man-Machine Information Systems. Sloan Management Review (Spring 1977), 29-46

8. Nehls, Carl Custodial Package Tracking at Federal Express In: Managing Innovation: Cases from the Service Industries, Bruce R. Guile and James Brian Quinn, Eds. National Academy Press 1988

9. Dyson, Esther Comments in proprietary newsletter Release 1.030 December 1987 
10. Rockoff, M.L. \& Stroll, D.M., Some Observations on IT Investment and Productivity in Financial Services, for: ACM SIGOIS Workshop on the Impact and Value of Information Systems, May 2-3, 1989

11. Keen, Peter G. W. Value Analysis: Justifying Decision Support Systems MIS Quarterly (March 1981) $1-15$

12. Flores, Fernando, Michael Graves, Brad Hartfield and Terry Winograd Computer Systems and the Design of Organizational Interaction. ACMTOIS 6, 2 (April 1988), 153-172

13. Clement, Andrew and C.C. Gotlieb Evolution of an Organizational Interface: The New Business Department at a Large Insurance Firm. ACM TOIS 54 (October 1987), 328-339

14. Richman, Tom Mrs. Fields' Secret Ingredient INC. (October 1987) 65 - 72

15. MIS Holds Together a Crumbling Cookie InformationWEEK, March 13, 1989 